\title{
Contributions of Working Conditions on Teachers' Attitude in School Settings of Nepal
}

\author{
Anan Lama 1, Milan Shrestha \\ 1 V.S. Niketan Education Foundation \\ 2 Kathmandu University School of Education \\ * Corresponding author: milanshrestha313244@gmail.com
}

\begin{abstract}
Article History
Received 2020-01-26

Revised 2020-02-18

Revised 2020-03-17

Accepted 2020-04-18

Published 2020-05-04
\end{abstract}

\section{Keywords}

Building conditions,

Maslow Hierarchy of Needs,

Motivation,

Teacher's attitude,

Working conditions,

\section{How to cite?}

Lama, A., \& Shrestha, M. (2020).

Contributions of Working Conditions on

Teachers' Attitude in School Settings of

Nepal SEISENSE Journal of

Management, 3(3), 23-33.

doi:10.33215/sjom.v3i3.298

Copyright (C) 2020 The Author(s)

(cc) BY

\begin{abstract}
Purpose- Working conditions play a vital part in shaping the attitude of teachers. In this context, researchers intend to assess the relationship between working conditions and attitudes of teachers.

Design/Methodology- Philosophically, this study is guided by a post-positivist paradigm utilizing the survey design. The data in this study were collected from the teachers of community schools of the Kathmandu district using the questionnaire My Classroom Appraisal Protocol (MCAP). Then, data were examined by inferential statistics like t-test and linear regression, respectively. After this, the derived findings were then interpreted through the perspective of the Maslow Hierarchy of Needs (MHN).

Findings- This study showed a moderate association between the working condition and the teachers' attitudes. Furthermore, this study concludes that the building condition of school plays a crucial role in shaping the teachers' attitude. Finally, this research established that working conditions significantly enhances the attitude of teachers.

Practical Implications- This study is expected to be beneficial to school leaders and forthcoming researchers for making positive changes in the education system of Nepal.
\end{abstract}




\section{Introduction}

Job performances of the teacher are crucial organizational behavior to achieving success in school. The job performance of teachers is associated with the working condition (Kahya, 2007) of school and their attitude (Harthy et al., 2013) towards the job. The working condition terms as a school building, and it refers to the setting of the classroom where the teaching-learning process takes place (Okon \& Sole, 2006). Moreover, the working conditions represents the setting of tables, chairs, writing boards, the sitting arrangement, books, audiovisual equipment, light, thermal conditions, and hardware of educational technology in the classroom (Farombi, 1998). Thus, working conditions play a vital role in shaping the teachers' attitude (Earthman \& Lemasters, 2009; Leigh, 2012) to their job. An attitude is a response, credence, and perception toward something or someone. It is a hidden process that occurs within an individual on a certain inducement (Oskamp \& Schultz, 2004). Teachers' attitude is inspired by their working conditions. The satisfactory working conditions motivate the work, whereas the unsatisfactory working conditions have lower job satisfaction and low commitment (Corcoran et al., 1988) among teachers. The increment of motivation and reducing job satisfaction as well as commitment due to working conditions are respectively the positive and negative outlook of the teacher's attitude.

The teachers' attitude is affected by working conditions like light, thermal status, and condition of the equipment. Appropriate light can enhance the productivity of teachers, whereas glare hampers teachers' effectiveness (Lewy et al., 1982). As well as, Heschong Mahone Group (HMG, 1999) also found effective teaching-learning takes place under natural daylight as students tend to scores 7 to 18 percent higher than those who study in less sunlight. Similarly, Harner (1974) confirms the optimum temperature as 68-74 degrees Fahrenheit of the classroom for the teaching-learning process. The decreasing or increment in this ideal range of temperature has physiological effects on teachers. Likewise, Schneider (2003) found that inadequacies in working conditions like furniture, the conditions of walls, the ceiling, and floor play a vital role in shaping teachers' attitudes. Therefore, the relationship between the working conditions and the teachers' attitude is associated with their performances. Thus, for effective performance, teachers must have good working conditions (Corcoran et al., 1988).

Furthermore, the working condition and teacher's attitude are associated with motivation theory as Maslow's Hierarchy of Needs (MHN). As stated by Maslows (1954), the employee in an organization is influenced by their current needs. The improvement of working conditions is referred to as the need among teachers. They have strong desires to improve their work condition, and its accomplishment reflects their attitude. More specifically, the improvement of working conditions switches motivation to perform jobs among teachers. A study conducted by Davis and Newstrom (2002) mentioned that until and unless factors such as working conditions are fulfilled, teachers will be dissatisfied and ineffective. Therefore, satisfactory working conditions arise the motivation, and it further produces better attitudes (Jerome, 2013) and fewer complaints from teachers.

In connection with Nepal regarding working conditions, the government of Nepal hardly invests much of its budget to improve the working conditions in the community schools. The Ministry of Education (MOE, 2016a) of Nepal states that about 65 percent of the community school budget is allocated for salaries and remuneration, followed by program costs at 27.2 percent, management, and administrative costs 7.4 percent. Apart from this, to expand the education system, many schools were constructed along with the implementation of the School Sector Development Plan (SSDP) using locally raised funds. But the drawback of such collaboration between the schools and the public is poor in terms of construction of the school buildings. This situation is further worsened after the earthquake in April and May 2015, which damaged around 35,000 classrooms (MOE, 2016b). Similarly, Wagley (2012) concluded that one of the factors of the poor performance of community schools is due to poor working conditions. In this context, the working condition is a big problem for teachers 
and students in Nepal (Subedi, 2017). Furthermore, Subedi (2017) also reveals that the physical infrastructures of the school building conditions were not good for teaching and learning.

Therefore, teachers are the key stakeholders in running the educational system successfully. Without them, our education system cannot prosper in the long run (Timalsina, 2008). Nevertheless, a study conducted by Parajul and Das (2013) states the performances of community school teachers are unsatisfactory. Although there can be many factors in the unsatisfactory performance of the community school. In this study, the researcher wants to know whether working conditions enhance the attitude of school teachers. Here, the researcher is concerned with the working condition of the community school teachers in the Kathmandu district and how they perceive their attitudes towards it. Thus, researchers tried to investigate the contribution of working conditions on the teacher's attitude. For achieving these purposes, the researcher raises the question as to what is the association concerning working conditions and attitudes of teachers?

\section{Literature Review}

\section{Teachers' Attitude in School Context}

Teachers' attitude is formed by different factors. Attitude is developed through a pattern of beliefs over a certain period. These beliefs are generated as we gain experience, knowledge, and a person generates two types of attitude, i.e., positive and negative attitude (Bain et al., 2010). Positive attitude in teachers forms a foundation for teaching and learning, whereas negative attitude hinders them (Mantle-Bromley, 1995). Proper working conditions in schools reflect that the educational leader is serious about education. However, if the working condition is not good, it harms the attitude of teachers, which may result in absenteeism and unwillingness to work (Corcoran et al., 1988). A study conducted by Agyenmang (1993) found that one of the key factors to a successful teacher was a qualification. Nevertheless, teachers who are academically and professionally qualified but do not have an essential working environment results in lower dedication than teachers who have a good working environment (Phanice, 2017). All in all, teachers' attitude is a concern for educational leaders to make effective and efficient teaching and learning environment.

\section{Structural Setting of Working Condition}

Working condition governs a crucial role in the process of teaching-learning activities (Ahunanya \& Ubabudu, 2006). It is also referred to as the classroom assessments of school teachers. The good working conditions include the placement of the classroom, availability of furniture, equipment, laboratories, and so on. If these working conditions are adequate, it helps and enhances the comfort and safety of both teachers and students (Knezevich, 1975). So, the working conditions of the classroom are the minimum resources required for an effective school (Adegbesan, 2007). Thus, the working condition in an educational institution is one of the most important assets to consider for teaching and learning. Furthermore, the structural setting of the working conditions (classroom) for teachers is very vital for teaching-learning. It helps the teachers and the students to get comfortable and makes the working condition better. For instance, lighting, acoustics, temperature, air quality, classroom layout are some of the structural working conditions to enhance better teaching-learning.

\section{Maslow's Hierarchy of Needs}

A motivation theory (MHN) proposed by Maslows (1954) believes that human has certain needs. This theory elucidated five hierarchical needs that are essential for an organization and its employees' performance and attitude (Mullins, 2010). In connection with MHN, until the basic needs (Physiological and Safety) are fulfilled, there will be no demand for higher-order needs (Belongingness and Love, Esteem, and Self-actualization). In this study, working condition is considered as teachers' basic needs for performing their job effectively. A study conducted by Jerome (2013) concluded that this theory is pertinent for a better work environment, employees' attitude, and performance. 


\section{Relationship between Work Settings and Teachers' Attitude}

Several authors like (Earthman \& Lemasters, 2009; Nichols, 2018) have done studies about the effect of working conditions on the attitudes of teachers. They revealed the affirmative relationship amid the quality of school building and attitudes of teachers. More specifically, the results portrait that the attitude of teachers in a good work setting has better overall scores. This result is analogous to Leigh (2012) where the author constructed a theoretical framework shown below in figure 1.

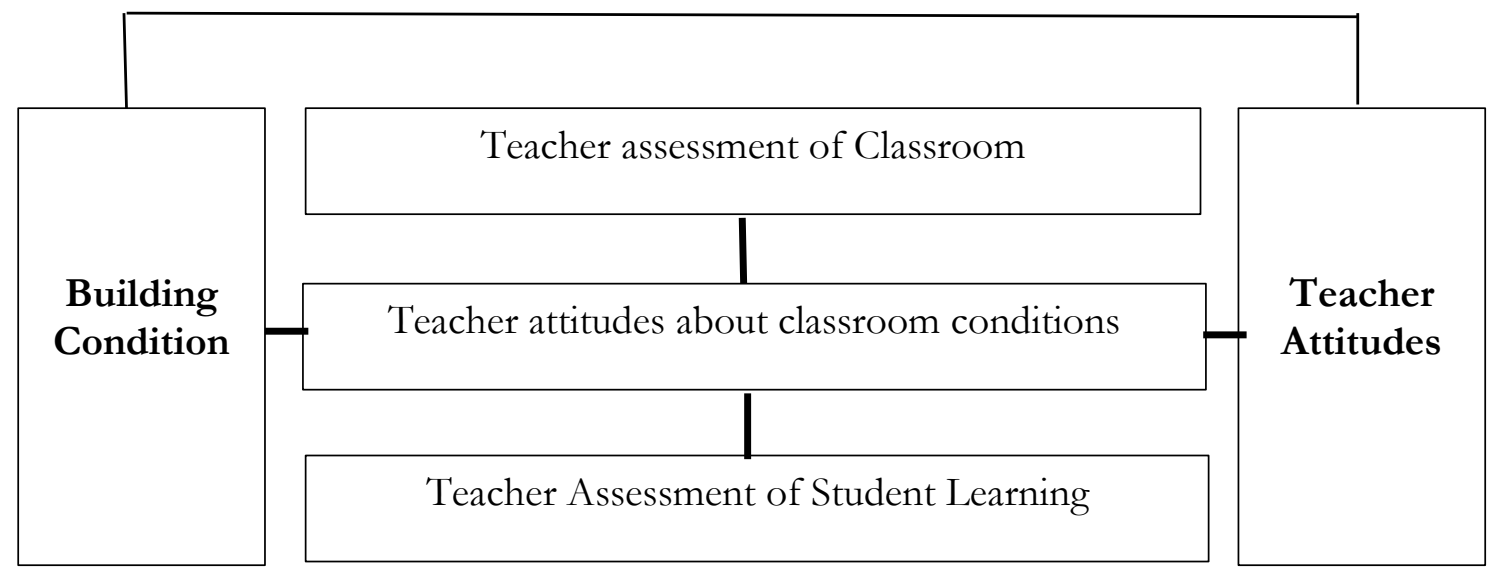

Figure 1 - Leigh Model about Building Condition and Teacher's Attitude

Adopted from Leigh (2012)

The Leigh's theoretical construct explored how the building condition affects teachers' attitudes. This study concluded that the attitude of teachers was influenced by the building condition of schools. Moreover, it figures out that teachers in satisfactory buildings had an overall better attitude than teachers in unsatisfactory buildings. The notable thing in this theory is that the building conditions are one of the most crucial factors which reflect the working conditions of teachers. Thus, an inadequate working condition in a school creates stress in the teaching-learning process (Abel \& Sewell, 1999). A study conducted by Morris (2003) supports that a poor working condition trigger student to back down, which affects students learning. In this context, Lowe (1990) states of the inability to control classroom temperature hampers teachers' and students' performance. Schools with inadequate working conditions like poor acoustics, poor buildings, and lack of thermal controls affect high teachers' turnover. They seek employment elsewhere, which disrupts the curriculum, and ultimately students' learning (Buckley et al., 2004). Therefore, proper management of working is vital for an effective teachinglearning experience.

\section{Theoretical Framework}

The concept of the theoretical framework was modified from Leigh (2012) concept, which focuses on building conditions and teachers' attitudes. Considering it, there have been many theories linked with the understanding of attitudes in the workplace. Here, the researcher has seen the effects of work settings on the attitudes of teachers through the lens of MHN. It focuses on the lower-order (basic) needs of teachers because the working condition of the school is a minimum requirement for the teaching-learning process. It means that the unsatisfactory work condition hampers the employee's attitude. Considering it, the working condition and attitudes of teachers were referred to as Input and Output, respectively. Thus, the researcher tries to ascertain the influence of working conditions and teachers' attitudes with MHN as in figure 2. 


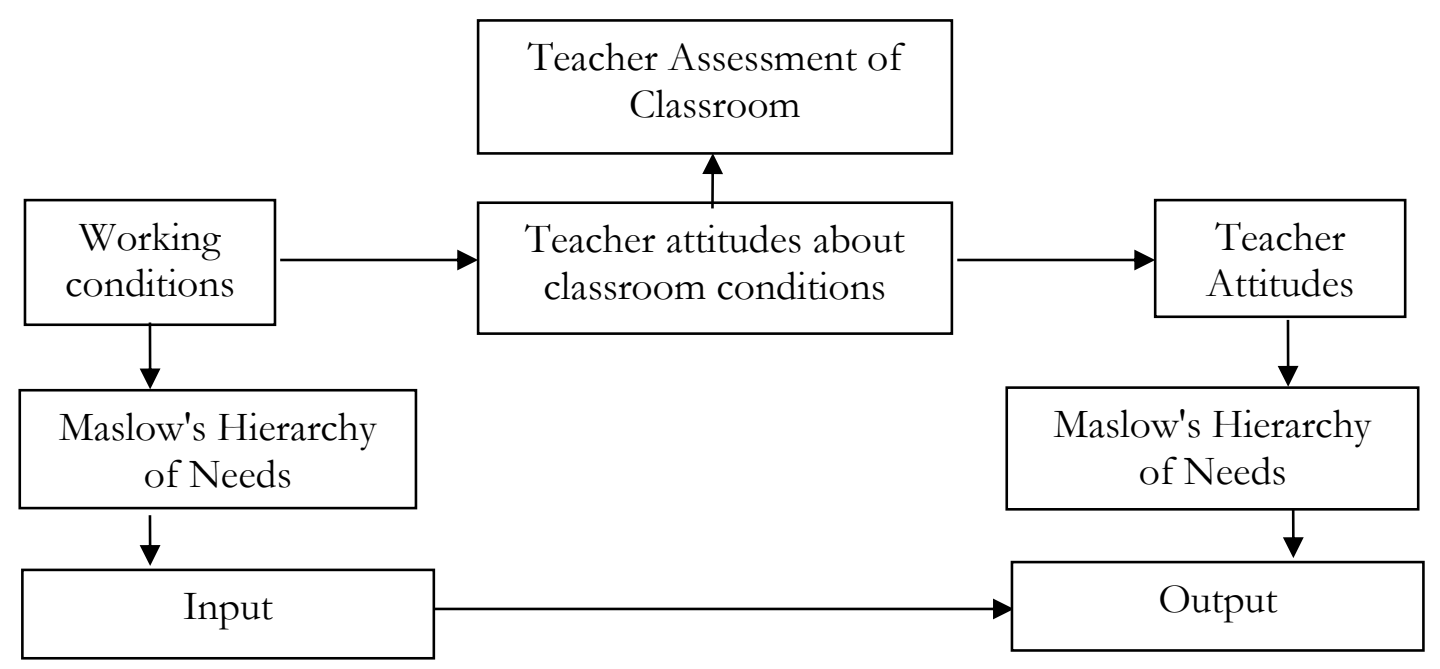

Figure 2 - Theoretical Framework

Idea modified from (Leigh, 2012)

Finally, based on this theoretical framework and literature reviews, this study set hypothesis as;

Hypothesis: There are no effects of working conditions on teachers' attitudes.

\section{Methods}

\section{Research Design}

This study follows the post-positivist philosophy, which advocates the single truth as the contribution of working conditions on the attitude of teachers. Then, based on the post-positivist research paradigm, it employed a descriptive research design. The descriptive study was conducted utilizing a field-based survey. This research design generalized the teachers' attitudes towards their working conditions. After this, the researcher used the Yamane (1967) formula to obtain the required sample size ( $\mathrm{n}=383$ ) by cluster sampling from 4283 number of community school teachers as population (DEO, 2013) of this study. More specifically, the district education office of Kathmandu has divided these schools into 23 different clusters; four clusters were randomly selected by one-stage cluster design through a lottery method. The reason why the researcher selected four clusters was that the pilot study showed that, on average, there were around 25 teachers in one community school in the Kathmandu district. This allowed the researcher to estimate the target sample size. The total number of community schools from the randomly selected cluster was thirty-three schools. In this way, the researcher collected 383 responses by visiting all 33 schools.

\section{Instrumentation and Data Collection Process}

To assess the working condition and measure the attitude of teachers, a survey questionnaire (MCAP) constructed by Earthman and Lemasters (2009) was adopted and contextualized it in the Nepali context. In the first phase, the tool was translated into the Nepali language so that the teacher could easily understand it. Then, the questionnaire is composed of two sections; working conditions (assess by classroom assessment) and attitudinal assessment of teachers. After this, the questionnaire was employed in pilot testing to ensure its internal consistency (Rattray \& Jones, 2007). For this purpose, the pilot study was conducted in four community schools of Kathmandu district, which were selected randomly and were not included in the main study. More specifically, the researcher took 37 respondents (teachers) for a pilot study considering the rule set by Treece and Treece (1982), which recommended selecting ten people for a pilot study from a population of 100 people. Then, the Cronbach's alpha value is obtained more than 0.7 in all sections of the MCAP questionnaire, which 
further established its internal consistency (Hertzog, 2008). In addition, the errors seen in the questionnaire during piloting were also addressed to finalize it.

Finally, the questionnaire was distributed among respondents with giving instructions about the way of responding to each question. Then, I requested them to fill the questionnaire and return it in the next days to the researcher. After the completion of the filling questionnaire, the researcher collected it and giving thanks to all respondents.

\section{Method of Data Analysis}

After gathering the data, it was scrutinized through regression analysis to measure the association between working (classroom) conditions and attitudes of teachers. Finally, the derived findings were viewed with the perspective of MHN.

\section{Results}

\section{Assumptions for Parametric Measures}

Even though there are different methods of analyzing data, this study followed the parametric method as regression analysis with Karl Pearson correlation to assess the relationship between working conditions and attitude among school teachers. However, to conduct parametric tests one must warrant normality of data along with certain assumptions like a) random independent sampling from the $\mathrm{k}$ population, $\mathrm{b}$ ) scale level of measurement, c) the dependent variable is distributed normally (Hecke, 2010), d) linearity, e) no autocorrelation, and f) correlation and absent of multicollinearity (Sreejech et al., 2014). Firstly, the sample is randomly selected from schools of Kathmandu district, and it ensured the assumption of random independent sampling in this study. Secondly, the assumption of scale level measurement is fulfilled by the Likert scale, which encompasses five levels of responses in every item. Then, the remaining assumptions were fulfilled as follows:

\section{Assumption of Normality}

The normality assumption was ensured with the help of Skewness and Kurtosis in this study. More specifically, the Skewness and Kurtosis of Classroom Assessment (Zskew [-.937] and Zkurt [1.620]) and Attitudinal Assessment (Zskew [-.265] and Zkurt [-.007]) is derived between the range of +1.96 to -1.96 which ensured that data is normally distributed (Ghasemi \& Zahediasl, 2012).

\section{Assumptions of no Autocorrelation}

To find out whether the data set has an autocorrelation issue, the Durbin-Watson statistic test was used. The value of Durbin Watson is measured to calculate autocorrelation errors, which should fall within 1.5 to 2.5 to be free from independent errors (Tabachnick \& Fidell, 2001). The first autocorrelation was calculated assuming classroom assessment as constant (predictor) and dependent variable as an attitudinal assessment from which the value of Durbin-Watson was 1.791. The result of Durbin-Watson 1.759 lies within 1.5 to 2.5, and it signified that the data is the absence of autocorrelation.

\section{Assumption of Linearity}

Linearity assumes that the dependent and independent variable must have a linear relationship, which means the outcome variable and predictor variable must lie on a straight line (Field, 2009). So, nonlinearity would shape the scatter plot to curve; however, the figure 3 presented below showed linearity. 


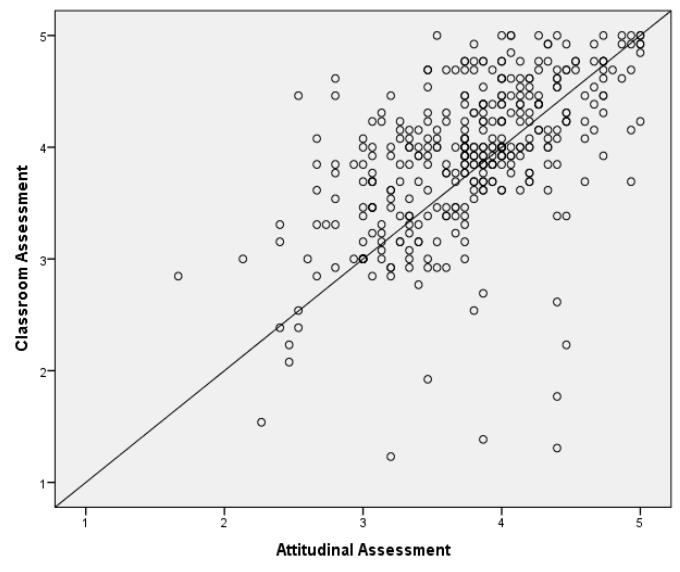

Figure 3 - Linearity between Working Condition and Teachers' Attitude

\section{Assumptions of Correlations and Absent of Multicollinearity}

Besides normality and linearity, to conduct a regression analysis, one should also verify if there are excessive correlations among variables. If the data do not have extensive correlations $(r>.90)$ between variables, the dataset is then known to be multi-collinearity free (Field, 2009). In this context, the derived values of correlation $(\mathrm{r}=.554)$ show that variables do not have an excessive correlation matrix between classroom assessment and attitudinal assessment. Considering these statistical values, none of the variables have excessive correlation among them $(r<.90)$. Therefore, it is assumed the data are free of multicollinearity. In addition, it is also important to check the variance inflation factor (VIF). The derived result of VIF (Classroom assessment $=$ 1.666 and Attitudinal assessment $=1.238$ ) is lesser than 10 with tolerance (Classroom assessment $=.600$ and Attitudinal assessment $=.808$ ) not exceeding 1 in multicollinearity test (Field, 2009). Therefore, it is assumed that variables were not subjected to multicollinearity.

Overall, the fulfillment of these above criteria ensured the assumptions of the parametric test further allows the researcher to perform Karl Pearson Correlation and regression analysis in this study.

\section{Effects of Working Condition on Teachers' Attitude}

The researcher examines the relationship between the working condition and how it affects teacher attitude. After the test of assumptions that were necessary for simple regression, the regression model $(y=a+b x)$ was used, where y and $\mathrm{x}$ refer to Attitudinal assessment (dependent variable) and Working condition (independent variable), respectively. Likewise, "a" and "b" were denoted as constant (y-intercept) and regression coefficients (slope), respectively. In line of this regression model, the researcher derived the statistical output in table 1.

\section{Table 1 - Regression Analysis between Working Condition and Teachers' Attitude}

\begin{tabular}{|c|c|c|c|c|c|c|c|c|c|c|}
\hline \multirow{2}{*}{ Model } & \multicolumn{2}{|c|}{$\begin{array}{l}\text { Unstandardized } \\
\text { Coefficients }\end{array}$} & \multirow{2}{*}{$\begin{array}{l}\begin{array}{l}\text { Standardized } \\
\text { Coefficients }\end{array} \\
\text { Beta }\end{array}$} & \multirow{2}{*}{$\mathrm{T}$} & \multirow{2}{*}{ Sig. } & \multirow{2}{*}{$\mathrm{R}$} & \multirow{2}{*}{$\begin{array}{l}\mathrm{R} \\
\text { Square }\end{array}$} & \multirow{2}{*}{$\begin{array}{l}\text { Adjusted } \\
\text { R Square }\end{array}$} & \multicolumn{2}{|c|}{ ANOVA } \\
\hline & B & $\begin{array}{l}\text { Std. } \\
\text { Error }\end{array}$ & & & & & & & $\mathrm{F}$ & Sig. \\
\hline (Constant) & 1.85 & .15 & \multirow{2}{*}{.55} & 12.08 & .00 & \multirow{2}{*}{$.55^{\mathrm{a}}$} & \multirow{2}{*}{.31} & \multirow{2}{*}{.31} & \multirow{2}{*}{161.56} & \multirow{2}{*}{.00} \\
\hline $\mathrm{CA}$ & .49 & .04 & & 12.71 & .00 & & & & & \\
\hline
\end{tabular}

* Dependent Variable: Attitudinal Assessment, CA = Classroom Assessment (working condition)

$*$ Correlation is significant at the 0.01 level (2-tailed) 
The value of correlation $(\mathrm{R})$ is revealed as .55 between the working condition and attitude of teachers in Table 1. Considering it, the interpretation of (Asuero et al., 2006) for measuring the strength of the correlation, the derived value of $\mathrm{R}$ signifies that there is a moderate degree of association amid the working condition and attitudes of teachers. The result of $\mathrm{R}$ Square 31 percent signifies that attitude can be predicted from the working condition. Similarly, the derived values from ANOVA indicate that the regression model is significant as $\mathrm{F}=$ $161.567, \mathrm{p}<.000$. It represents that the working condition could significantly predict teachers' attitudes. Furthermore, the Table 7 , portrays the regression model as $\mathrm{Y}=1.85+.49 \mathrm{x}$. This regression equation showed that when there is a unit change in working conditions, the teachers' attitude is supposed to be increased by .490 units significantly as the $\mathrm{p}$-value $(=.00)$ is less than the alpha value of 5 percent. This divulges that working conditions significantly affect the teachers' attitude.

\section{Discussion}

This research obtained significant alteration amid teachers' attitude considering their school building conditions while assessing the classrooms. The hypothesized statement of this study validates the findings of Earthman and Lemasters (2009), and Leigh (2012). They found significant differences between teachers' attitude considering satisfactory and unsatisfactory building condition. Both studies used the same questionnaire called MCAP to measure the attitude of teachers and they divulge that the attitude of teachers in the satisfactory building was better than those of unsatisfactory building. Contrary to it, this study didn't categorize the satisfactory and unsatisfactory school building across the attitudes of teachers. However, the findings of Earthman and Lemasters (2009), and Leigh (2012) supports the finding of this study because it also reveals that the working conditions make differ in teachers' attitude in school. Similarly, a study conducted by Schneider (2003) reported that poor lighting, noise, inadequacy in recreational facilities, lack of workspace in the classroom affected the career decisions and teachers' attitude. The sample for the study was collected from Chicago and Washington D.C. Teachers were told to evaluate their classroom lighting, thermal status, and air quality. He concluded that working condition has a relationship between teachers' satisfaction level and attitude. The study of (Schneider, 2003) supports the finding of this study that the working condition has a significant relationship with teachers' attitudes.

Likewise, Buckley et al. (2004) also examine the teachers' attitude and condition of facilities in their workplace. Before performing this research, they noticed that many teachers leave their job. So, they want to know its reason and finally, they concluded that the working condition plays a role in teachers' turnover. Thus, the results of this study validate the findings of Buckley et al. (2004) that the working condition plays a vital role and is a significant factor in developing the teachers' attitude. Moreover, the outcome of this research is aligned with Ruszala (2007) where scholar also divulges a moderate degree of correlation between the satisfaction of teachers and the condition of the school building. Furthermore, Isaiah (2003) concluded that the unsatisfactory building condition hampers teachers' job satisfaction and productivity. It insight that teachers in satisfactory school building conditions have more satisfaction and it results in a positive attitude in jobs. That's why a better building condition (working environment) is a prerequisite to shaping positive attitudes among teachers.

The influences of working conditions in attitudes among teachers are depending on their existing level of needs. Concerning it, Maslows (1954) states that human is driven by certain needs and if basic needs are not fulfilled, they cannot think about higher needs. So, teachers are motivated in their job when they have fulfilled their needs as improvement in their working conditions. Furthermore, when their previous needs were accomplished, they will further be motivated to fulfilling a higher level of needs. For instance, the good working condition is considered as a basic need for teachers to effective facilitation of students in the classroom. This theoretical perspective of MHN applies to this study where it established that the working condition influences the attitudes of teachers. This result satisfies Maslow's lower order need because Isaiah (2003) claims that the teachers who had unsatisfactory building conditions do not have a better overall attitude towards their job performances. 
Furthermore, in a nutshell, this study reveals that the teacher from the satisfactory building condition had an overall better attitude. This indicates that if teachers are provided better working condition it helps to motivate them.

\section{Conclusion}

The finding from this study leads to conclude that having a satisfactory school building condition is vital for a better attitude of teachers. Additionally, this proves that thermal, lighting, condition of furniture and equipment can make a difference in shaping teachers' attitudes. Furthermore, it reveals that satisfactory work settings (building environment) have an enthusiastic attitude regarding their job. These teachers enhance high educational achievement among students who have unsatisfactory building conditions. In a nutshell, this study demonstrates how a physical structure of a school building and their working condition shapes teachers' attitude which is very vital in the long run of the modern Nepali pedagogical era.

\section{Implications}

The insight knowledge from this scholastic work can be worthwhile to educational leaders like principal and impending researchers. On the first hand, the school principal refers to one of the most responsible school leaders to run the school effectively and efficiently. Principals can maintain and update what is required so that facilities are not the reason for obstructing the teaching-learning process. Furthermore, principals can consider the feedback from teachers about their learning experience so that they could improve their learning environment. On the other hand, this study can act as a guideline for the coming researcher to investigate similar types of study. Even though the focus of this study was on working conditions and teachers' attitudes, future researchers can continue research focusing on qualitative and mixed-method research. This research will add strength in finding the relationship between the working condition and teachers' attitudes. Lastly, future researchers can focus on the effect of school facilities on the academic performance of teachers. These variables would broaden the research and give a deeper understanding of the issues which will reinforce the education system of Nepal and even of other countries.

Funding: This research received no external funding.

Conflicts of Interest: The authors declare no conflict of interest.

\section{References}

Abel, M. H., \& Sewell, J. (1999). Stress and burnout in rural and urban secondary school teachers. The Journal of Educational Research, 92(5), 287-294. https://doi.org/10.1080/00220679909597608

Adegbesan, S. O. (2007). Adequacy of school facilities in Nigerian Vocational and Technical Colleges: An Empirical Study. Nigerian Journal of Educational Administration and Planning, 7(2), 169-177.

Agyenmang, D. K. (1993). Sociology of education for African students. Accra Black Mask Ltd.

Ahunanya, S. I., \& Ubabudu, M. C. M. (2006). Enrolment, facilities and financial allocation in Lagos state higher education: Implication for quality graduates. Nigerian Journal of Educational Administration and Planning, 6(1), 153-164.

Asuero, A. G., Sayago, A., \& Gonzalez, A. (2006). The Correlation Coefficient: An Overview. Critical Reviews in Analytical Chemistry, 36, 41-59. https://doi.org/10.1080/10408340500526766

Bain, S. K., McCallum, R., Bell, S. M., Cochran, J. L., \& Sawyer, S. C. (2010). Foreign language learning aptitudes, attitudes, attributions, and achievement of postsecondary students identified as gifted. Journal of Advanced Academics, 22(1), 130-156. https://doi.org/10.1177/1932202X1002200106

Buckley, J., Schneider, M., \& Shang, Y. (2004). Fix it and they might stay: School facility quality and teacher retention in Washington D.C.. Teachers College Record, 107(5), 1107-1123. 
Corcoran, T. B., Walker, L. J., \& White, J. L. (1988). Working in urban schools. Institute for Educational Leadership. https:// files.eric.ed.gov/fulltext/ED299356.pdf

Davis, K., \& Newstrom, J. W. (2002). Organizational behavior: human behavior at work (11 ed.). McGraw-Hill Companies, Inc.

District Education Office [DEO]. (2013). Shaikhsik manjari 2070 [Educational collection 2070]. http://deokathmandu.gov.np/allcontent/Detail/25

Earthman, G., \& Lemasters, L. (2009). Teacher attitudes about classroom conditions. Journal of Educational Administration, 47(3), 323-335. https://doi.org/10.1108/09578230910955764

Farombi, J. G. (1998). Resource concentration, utilization and management as correlates of students' learning outcomes: A study in school quality in Oyo state (Unpublished PhD thesis). University of Ibadan.

Field, A. (2009). Discovering statistics using SPSS. Sage.

Ghasemi, A., \& Zahediasl, S. (2012). Normality test for statistical analysis: A guide for non statisticians. International Journal of Endocrinology Metabolism, 10(2), 486-489.

Harner, D. P. (1974). Effect of thermal environment on learning skills. The Educational Facility Planner, 12(2), 4-6.

Harthy, S. S. H. A., Jamaluddin, S., \& Abedalaziz, N. A. (2013). Teacher's attitude and performance: An analysis of effects due to teaching experience. International Interdisciplinary Journal of Education, 2(9), 888893.

Hecke, T. V. (2010). Power study of anova versus Kruskal-Wallis test. Journal of Statistics and Management Systems, 15(2), 241-247. https://doi.org/10.1080/09720510.2012.10701623

Hertzog, M. A. (2008). Considerations in determining sample size for pilot studies. Research in Nursing and Health, 31, 180-191. https://doi.org/10.1002/nur.20247

Heschong Mahone Group (HMG). (1999). Daylighting in schools: An investigation into the relationship between daylighting and human performance. http://h-m-g.com/downloads/Daylighting/schoolc.pdf

Isaiah, M. (2003). Linking the school facilities conditions to teachers' level of job dissatisfaction in the south central region of Botswana. International Review of Social Sciences and Humanities, 4(2), 196-205.

Jerome, N. (2013). Application of the Maslow's hierarchy of need theory; impacts and implications on organizational culture, human resource and employee's performance. International Journal of Business and Management Invention, 2(31), 39-45.

Kahya, E. (2007). The effect of job characteristics and working conditions on job performance International Journal of Industrial Ergonomics, 37(6), 515-523. https://doi.org/10.1016/j.ergon.2007.02.006

Knezevich, S. J. (1975). Management of school facilities in administration of public education Harper \& Row, Publishers.

Leigh, R. M. (2012). School facility conditions and the relationship between teacher attitudes (Unpublished PhD thesis). Virginia Polytechnic Institute and State University.

Lewy, A. J., Kern, H. A., Rosenthal, N. E., \& Wehr, T. A. (1982). Bright artificial light treatment of a manicdepressive patient with a seasonal mood cycle. American Journal of Psychiatry, 139, 1496-1498.

Lowe, J. M. (1990). The interface between educational facilities and learning climate (Unpublished PhD thesis). Texas A \& M University.

Mantle-Bromley, C. (1995). Positive Attitudes and Realistic Beliefs: Links to Proficiency. The Modern Language Journal 79, 372-386. https://doi.org/10.1111/j.1540-4781.1995.tb01114.x

Maslows, A. H. (1954). Motivation and personality. Harper.

Ministry of Education [MOE]. (2016a). National education accounts in Nepal: Expenditure for education 20092015. http:/ / uis.unesco.org/sites/default/files/nepal-nea-report.pdf

Ministry of Education [MOE]. (2016b). School sector development plan 2016-2023. http://www.moe.gov.np/assets/uploads/files/MOE_SSDP_Final_Document_Oct_2016.pdf 
Morris, R. (2003). The relationship among school facility characteristics, student achievement, and job satisfaction levels among teachers (Unpublished PhD thesis). University of Georgia.

Mullins, L. J. (2010). Management and organization behavior. Prentice Hall.

Nichols, A. (2018). The relationship between teacher attitudes regarding performance-related pay and teacher working conditions (Unpublished $\mathrm{PhD}$ thesis). Eastern Kentucky University.

Okon, J. E., \& Sole, M. A. (2006). Management of the Nigerian primary school plant: Perceptions for Effective Practice. Nigerian Journal of Curriculum Studies, 13(1), 139-146.

Oskamp, S., \& Schultz, P. W. (2004). Attitudes and opinions (3rd ed.). Lawrence Eribaum Associates Publishers. https://doi.org/10.4324/9781410611963

Parajul, R. D., \& Das, T. (2013). Performance of community schools in Nepal: A macro level analysis. International Journal of Scientific and Technology Research, 2(7), 148-154.

Phanice, K. (2017). Influence of school environment on job satisfaction of public secondary school teachers in Bungoma south sub county, Kenya (Unpublished PhD thesis). University of Nairobi.

Rattray, J., \& Jones, M. C. (2007). Essential elements of questionnaire design development. Journal of Clinical Nursing, 16, 234-243. https://doi.org/10.1111/j.1365-2702.2006.01573.x

Ruszala, J. (2007). The conditions of the high school facilities in the commonwealth of Virginia's metropolitan school divisions and the relationship to teacher satisfaction (Unpublished $\mathrm{PhD}$ thesis). The George Washington University.

Schneider, M. (2003). Linking school facility conditions with teacher satisfaction success. National Clearinghouse for Educational Facilities. http://www.ncef.org/pubs/teachersurvey.pdf

Sreejech, S., Mohanpatra, S., \& Anusree, M. R. (2014). Business research method: An applied orientation. Springer.

Subedi, B. P. (2017). Relationship between head teacher leadership attributes and school climate in community schools of Nepal (Unpublished PhD thesis). Kathmandu University School of Education.

Tabachnick, B. G., \& Fidell, L. S. (2001). Using multivariate statistics (4th ed.). Allyn and Bacon.

Timalsina, T. P. (2008). School effectiveness with preference to the public and private schools in Nepal (Unpublished MPhil dissertation). Kathmandu University School of Education.

Treece, E. W., \& Treece, J. W. (1982). Elements of research in nursing (3rd ed.). Mosby.

Wagley, D. (2012). Dropout of children from schools in Nepal. Norwegian Centre for Child Research: Norwegian University.

Yamane, T. (1967). Elementary sampling theory. Prentice-Hall. 